\title{
Influence of Gold Nanoparticles on the Photocatalytic Action of Titanium Dioxide in Physical-Chemical Parameters of Greywater
}

\author{
Hipólito Carbajal-Morán'", Javier F. Márquez-Camarena', \\ Carlos A. Galván-Maldonado' \\ 1 Universidad Nacional de Huancavelica, Facultad de Ingeniería Electrónica-Sistemas, Jr. La Mar № 755, \\ Pampas-Tayacaja, Huancavelica, Perú \\ * Corresponding author's e-mail: hipolito.carbajal@unh.edu.pe
}

\begin{abstract}
The objective of the work was to evaluate the influence of gold nanoparticles, obtained by laser ablation, on the photocatalytic action of titanium dioxide in the improvement of the physical-chemical parameters of domestic greywater, with visualization by means of a PLC. The YAG laser equipment was used for the production of spherical gold nanoparticles, whereas the Raman spectroscope allowed characterizing the different particles contained in aqueous solutions. The solar photoreactor programmable and viewable from PLC with connection to sensors allowed determining the variations of the $\mathrm{pH}, \mathrm{EC}, \mathrm{DO}$ and FCL parameters. The work consisted of a control group (greywater + titanium dioxide) and an experimental group (greywater + titanium dioxide + gold nanoparticles). The titanium dioxide doses for both groups were $0.5 \mathrm{mg} / \mathrm{L}$ and the gold nanoparticles were $0.20 \mathrm{ml}$ per liter of greywater only for the control group. The experiments were carried out on sunny days with the exposure periods of 30 and 60 minutes around solar noon with an average UV index of 13.35. Once the experiments were carried out, it was determined that the $\mathrm{pH}$ improved by $5.30 \%$, EC by $3.03 \%$, DO by $29.3 \%$ and FCL by $43.71 \%$, so that the gold nanoparticles dissolved in the aqueous solution of titanium dioxide with greywater positively influenced the improvement of the photocatalytic action of titanium dioxide in the physical-chemical parameters of greywater.
\end{abstract}

Keywords: water pollution, solar UV radiation, AuNPs, programmable logic controller.

\section{INTRODUCTION}

Greywater is an important additional source to meet the demand for water resources, due to the growing world population, for many uses other than human consumption [Mohamed et al., 2018]. According to research, water reuse leads to savings in the consumption of drinking water in homes ranging between $30 \%$ and 50\% [EMRC, 2011]. Therefore, this resource requires certain treatments to bring the value of the physicalchemical and microbiological parameters to adequate levels for the uses established in the regulations of different countries.

There are alternatives for the disinfection of water such as photocatalysis processes, these represent an option in the elimination of organic and inorganic compounds efficiently [Plantard et al.,
2021]. They have the characteristics that favor the reduction of pollutants in liquids, such as: reduced time in the inactivation of microorganisms, less toxicological residual effect, mineralization of compounds, decontaminating treatments in low concentration and minimal formation of byproducts, using sunlight as a source of energy [Rueda-Marquez et al., 2020].

Several investigations were carried out to improve the quality of polluted water, especially greywater; using the photoreactors coupled to parabolic systems exposed to solar UV radiation to improve the efficiency of the organic load removal and microbial disinfection [Almomani et al., 2018; de Oliveira Schwaickhardt et al., 2017].

Titanium dioxide is a photocatalyst chemical compound that allows shortening the exposure times of liquids in treatment with solar UV 
radiation [Abdel-Maksoud et al., 2018]. However, it requires improving the photocatalytic action with nanocomposites such as $\mathrm{Fe}, \mathrm{Au}$, among others [Lin et al., 2017]. Therefore, this experimental study was proposed to determine the influence of gold nanoparticles on the photocatalytic action of titanium dioxide in the physical-chemical parameters of greywater.

\section{MATERIALS AND METHODS}

\section{Raman spectroscopy}

Spectroscopic techniques are constantly used in the identification, characterization and elucidation of molecular structures and compounds, as well as in the monitoring and control of chemical reactions. They are based on the property that atoms and molecules have to absorb or emit energy in a certain region of the electromagnetic spectrum, which offers the information on the chemical and crystalline constitution of the sample [J. Sun et al., 2020]. When radiation is focused on a body, there may be a transition between its energy states and, depending on the region in which the incident radiation energy is located, different types of transitions occur, such as electronic transitions, which are commonly established in the ultraviolet or visible, rotational region, defined in the microwave, translational and vibratory region, the latter located in the visible, infrared or near infrared.

Raman spectroscopy is a scattering technique based on the Raman effect, discovered and published by Raman \& Krishnan [1928]. The effect is characterized by a change in the frequency of a small fraction of the incident radiation when it is scattered by molecules or crystalline structures. Scattering occurs through the interaction of molecules in a sample with monochromatic electromagnetic light. In this interaction, the incident photons excite the molecule that is initially at a vibratory level from the ground electronic state to a virtual state, from which it immediately recovers in three different ways.

In the first way (Figure 1a), elastic scattering occurs (Rayleigh scattering), by the principle of conservation of energy, the photon is scattered without changing its wavelength value, that is, the energy of the photon is the same before and after its interaction with matter [Das \& Agrawal, 2011]. In the second form (Figure 1b), it is of the Raman Stokes type, where the occurrence of inelastic dispersion (Raman effect) occurs when the molecule, upon returning from the virtual state to the ground state, acquires a lower level of energy compared to its initial level; if the molecule receives the energy through its interaction with the incident photon "the scattered photon" will lose the same amount of energy that the molecule has acquired $E=h v_{0} E=h\left(v_{0}-v_{1}\right)$ [Das \& Agrawal, 2011; Hou et al., 2013; Raman \& Krishnan, 1928].

However, in anti-Stokes Raman scattering (Figure 1c), the scattered photon acquires the energy dissipated by the molecules, $E=h\left(v_{0}-v_{1}\right)$ due to the Boltzmann distribution with $N / N_{0}=$ $e^{-(\Delta E / K T)}$, where $N$ is the number of molecules initially in the excited state, $N_{0}$ corresponds to the number of molecules initially in the ground state of vibration and $\Delta \mathrm{E}$ is an energy difference between these two states [Das \& Agrawal, 2011]. It is possible that, under ambient conditions, a finite number of molecules are already vibratory excited and, when interacting with electromagnetic radiation, end up losing energy.

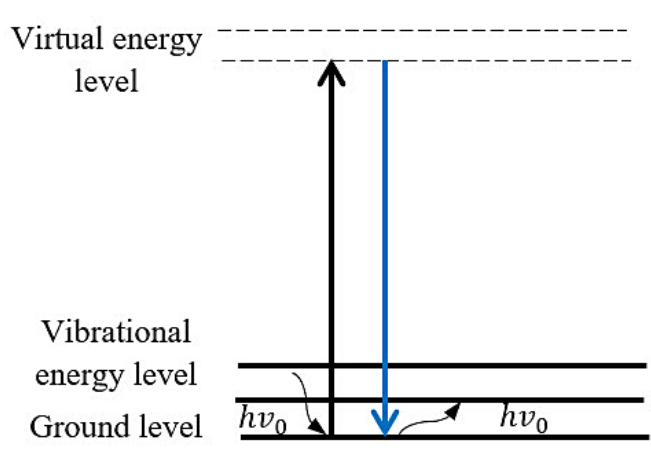

(a)

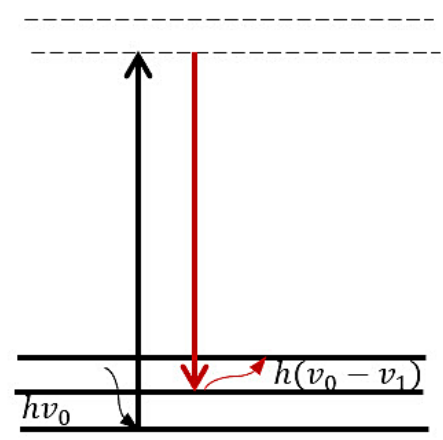

(b)

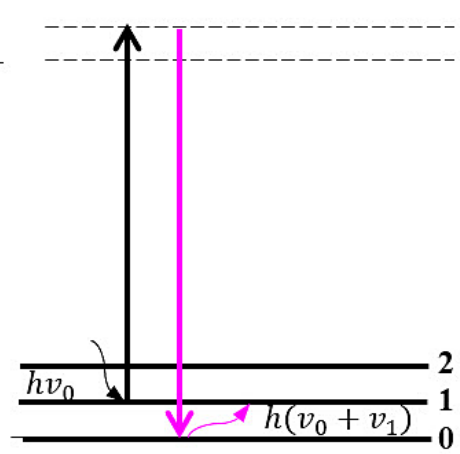

(c)

Figure 1. Electromagnetic radiation scattering: (a) Rayleigh scattering,

(b) Stokes Raman scattering and (c) Anti-Stokes Raman scattering 


\section{Greywater Raman spectroscopy}

The greywaters containing detergents and surfactants from washing clothes and showers was used in the research. It was initially subjected to Raman spectroscopy with an invisible laser radiation length of $785 \mathrm{~nm}$ and a power of $499 \mathrm{~mW}$ [AVANTES, 2019]. The result of the sample characterization is presented in Figure 2.

\section{Raman spectroscopy of titanium dioxide}

Titanium dioxide exists in nature in three main crystalline structures: rutile, anatase and brookite. Only rutile and anatase have the properties of interest for applications, because they are thermodynamically and environmentally cleaner and more stable [Mansfeldova et al., 2021].

Figure 3 shows the Raman spectrum of titanium dioxide $\left(\mathrm{TiO}_{2}\right)$ with three peaks; for a spectrum of $242 \mathrm{~cm}^{-1}$ there is an amplitude of $26547 \mathrm{ADC}$, for the spectrum of $444 \mathrm{~cm}^{-1}$ there is a peak amplitude of $52000 \mathrm{ADC}$ and for the spectrum of $611.37 \mathrm{~cm}^{-1}$ there is a peak amplitude of 43500 ADC. This configuration corresponds to the $\mathrm{TiO}_{2}$ of the rutile type [Ilie et al., 2017].

\section{Raman spectroscopy of gold nanoparticles}

The gold nanoparticles were generated by laser ablation in liquid medium with ultrapure water using the CD: ND: YAG equipment, for the spectrum of Figure 4 corresponds to spherical nanoparticles [Zhang et al., 2016]. The highest amplitude spectrum occurs at $1396.84 \mathrm{~cm}^{-1}$ which corresponds to the amplitude of 55960 ADC.

The localized surface plasmon resonance of gold nanoparticles is characterized using the MieGans model [Amendola \& Meneghetti, 2009]. By adjusting this spectrum, the average dimension of the nanoparticles is estimated to be $20 \mathrm{~nm}$. The aggregated gold nanoparticles present a plasmon resonance band with a characteristic red shift, according to the Mie-Gans model used to evaluate the size and concentration of the colloidal gold solution [Amendola \& Meneghetti, 2009].

\section{Solar ultraviolet radiation index}

The index of solar ultraviolet radiation (IUV), allows estimating the radiation on the surface of the photoreactor with wavelength $(\lambda)$ of the UV spectrum in the daily average range on the days of experimentation was around 13.35, which represents an extremely high index [Yamamoto et al., 2018], without the presence of cloud for the solar noon in the city of Pampas-Huancavelica-Peru, located at $-12.395361^{\circ},-74.872336^{\circ}$ at a height of 3246 meters above sea level. Solar UV radiation was measured by means of the UVM $30 \mathrm{~A}$ radiation sensor, which made it possible to determine the irradiance on the surface of the photoreactor with $\lambda$ of the UV spectrum from $200 \mathrm{~nm}$ to $370 \mathrm{~nm}$ [ElectroPeak, 2016]. This spectrum covers part of UVC radiation, UVB radiation and part of UVA radiation [Matallana-Surget \& Wattiez, 2013].

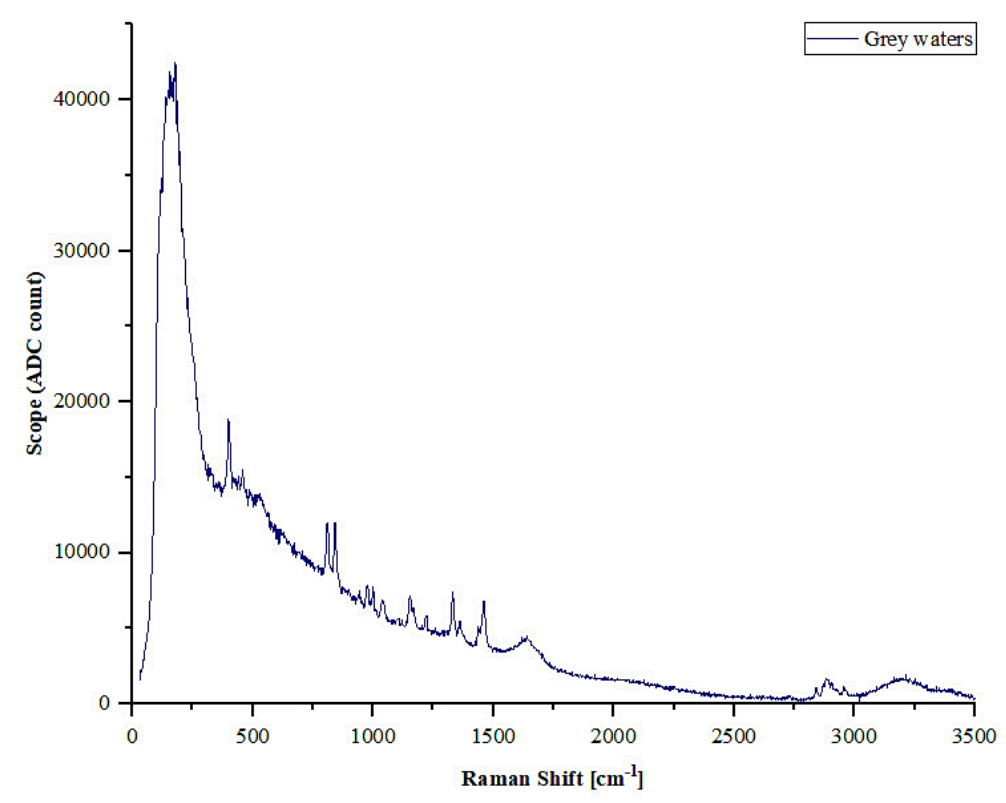

Figure 2. Characterization of greywater by Raman spectroscopy 


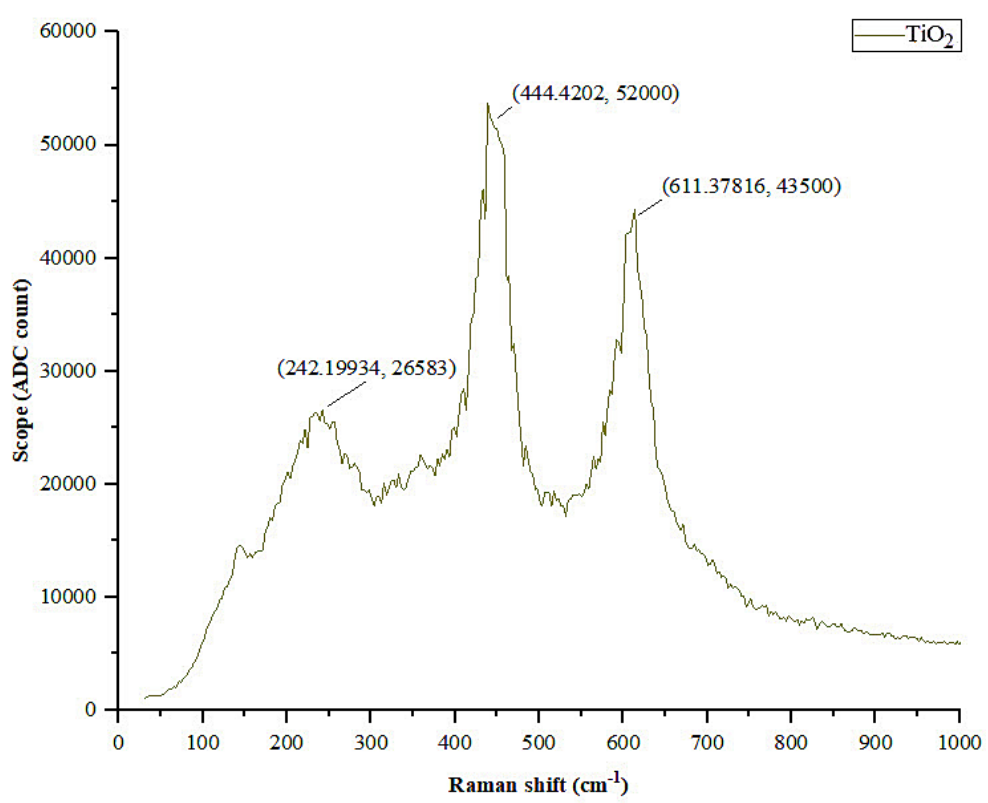

Figure 3. Characterization of rutile titanium dioxide by Raman spectroscopy

\section{Transmitters of physico-chemical parameters of water}

a) $\mathrm{PH}$ sensor - transmitter

The $\mathrm{pH}$ sensor in Figure 5 is an element that detects the current generated by the presence of hydrogen ions in water. The measure is in the range of $0-14$. The $\mathrm{pH}$ sensor was used in this work in conjunction with the transmitter, under the IP 68 protection certification for continuous immersion in water [BOPLA, 2019], the working temperature range is from $0{ }^{\circ} \mathrm{C}$ to $60{ }^{\circ} \mathrm{C}$, the communication of the measurements with the analog module of the programmable logic controller (PLC) is by analog signal from $4 \mathrm{~mA}$ to $20 \mathrm{~mA}$.

b) Sensor - transmitter of electrical conductivity Electrical conductivity relates the concentration of ions from dissolved salts and organic matter in water. The units in which it is measured are given in microsiemens per centimeter $(\mathrm{uS} / \mathrm{cm})$ [Boyd, 2020]. The sensor that measures this conductivity has an electronic probe that applies voltage at its ends to measure the resistance of the water, convert it into conductivity, and transmit

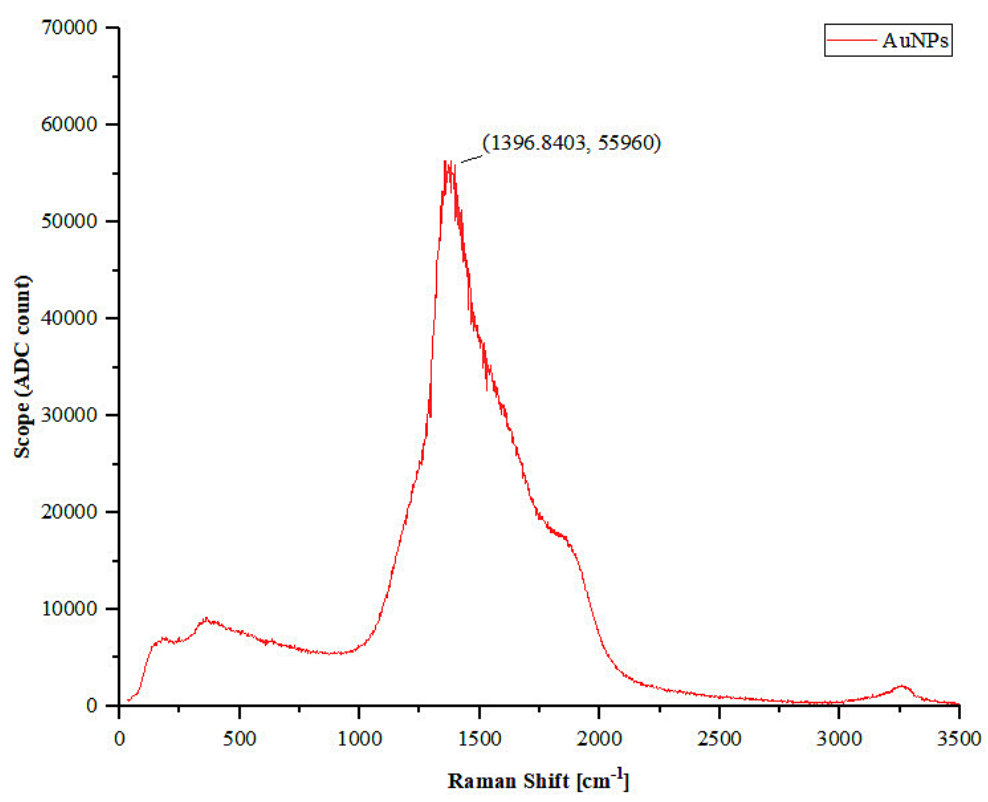

Figure 4. Characterization of gold nanoparticles by Raman spectroscopy 


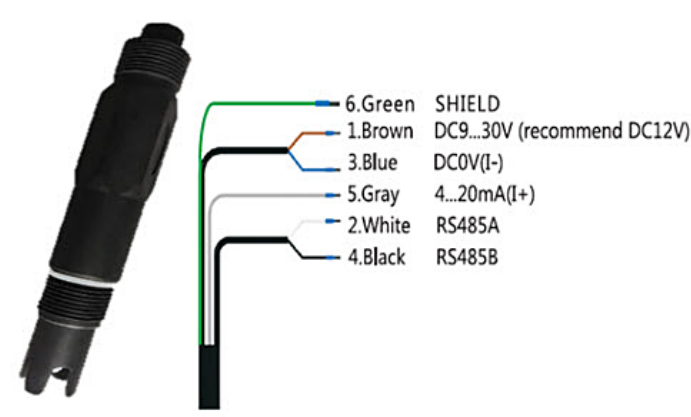

Figure 5. PH sensor - transmitter

its electrical equivalent from $4 \mathrm{~mA}$ to $20 \mathrm{~mA}$ to the analog module of the PLC.

c) Sensor - dissolved oxygen transmitter

Dissolved oxygen (DO) represents the amount of dissolved oxygen gas $\left(\mathrm{O}_{2}\right)$ in the solution (greywater) [Boyd, 2020]. The samples were measured online, their units are given in milligrams per liter (mg/L) [REMOND, 2019]. The device used is seen in Figure 6.

d) Sensor - free chlorine transmitter

Free chlorine has the ability to react with ammonia ions and organic compounds, forming combined chlorine. The sum of the chlorine combined with the residual chlorine gives the total chlorine [Boyd, 2020]. Recurrent free chlorine (FCL) has as a unit of measurement the milligram per liter per parts per million $(\mathrm{mg} / \mathrm{L} \mathrm{ppm})$. The device used is seen in Figure 7.

\section{Solar photocatalyst}

A photocatalyst consisting of a tubular reactor with a composite parabolic collector (CPC) was used [Carbajal-Morán et al., 2021]. Then two processes were executed in the solar photocatalyst; the first greywater treatment was carried out only with the use of titanium dioxide (Figure $8 \mathrm{a}$ ) and the second with the use of titanium dioxide in the same dose as the first one plus the gold nanoparticles (Figure 8b). The second

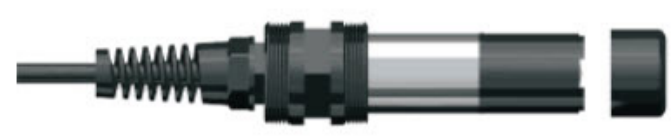

Figure 6. DO sensor-transmitter experimental treatment, began with the supply of greywater to the main process tank, it is where the rutile type titanium dioxide was mixed in the doses of $0.5 \mathrm{~g} / \mathrm{L}$ and gold nanoparticles in aqueous solution in doses of $0.2 \mathrm{ml} / \mathrm{L}$, after this process, the initial characterization of the greywater was carried out by measuring the $\mathrm{pH}, \mathrm{EC}, \mathrm{DO}$ and FCL parameters. The greywater under treatment is exposed to solar radiation in the photoreactor for periods of time of 30 and 60 minutes, with measurement and recording of the value of the parameters every $15 \mathrm{~min}$.

The human machine interface (HMI) of the photoreactor of Figure 9 is connected to a PLC and sensor-transmitters from an analog module. It presents the controls from the control panel that allowed: the homogenization of the mixtures in the main process tank, measurements of the parameters ( $\mathrm{pH}, \mathrm{EC}, \mathrm{DO}$ and $\mathrm{FCL})$ of the liquid under treatment. Likewise, it enable the automatic control of the exposure of the liquid under treatment to solar UV radiation for $30 \mathrm{~min}$ and $60 \mathrm{~min}$.

\section{RESULTS AND DISCUSSION}

Two types of mixes were made in the main process tank; the first considered the control group, which consisted of mixing $0.5 \mathrm{~g}$ of $\mathrm{TiO}_{2}$ per liter of greywater and for the second considered the experimental group, $0.5 \mathrm{~g}$ of $\mathrm{TiO}_{2}$ and $0.2 \mathrm{ml}$ of gold nanoparticles were mixed per liter of greywater. Both mixtures were homogenized by means of the mixing mechanism in the main tank. Then, they were characterized by Raman spectroscopy with radiation of $785 \mathrm{~nm}$ at a power of $499 \mathrm{~mW}$

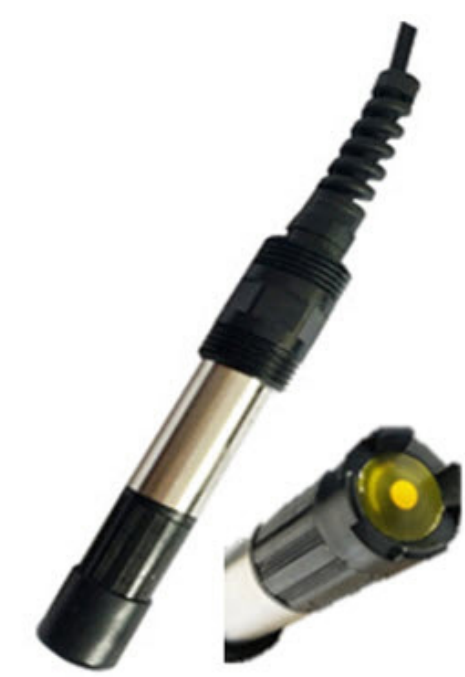

Figure 7. Residual chlorine sensor-transmitter 

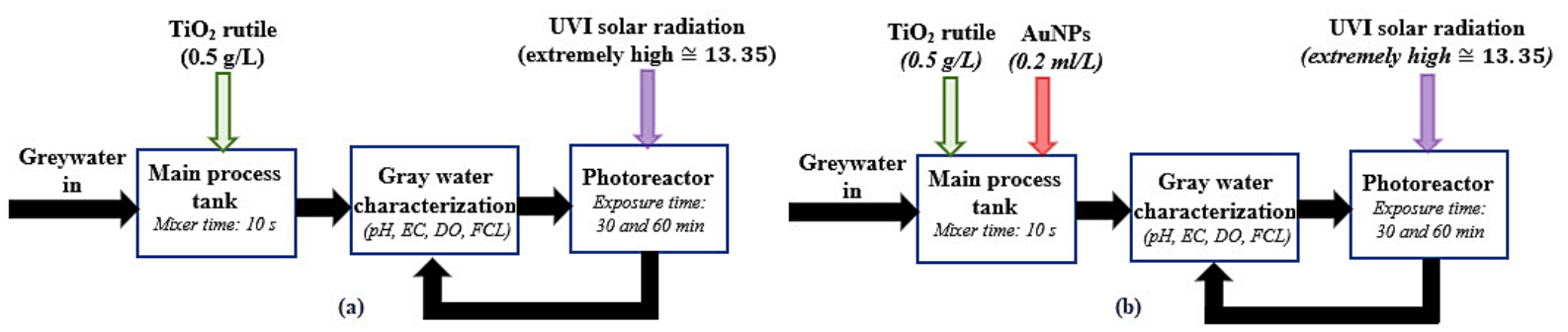

Figure 8. Flow diagram of the photocatalyst operation (a) for control group: greywater and titanium dioxide (b) for experimental group: greywater, titanium dioxide and gold nanoparticles

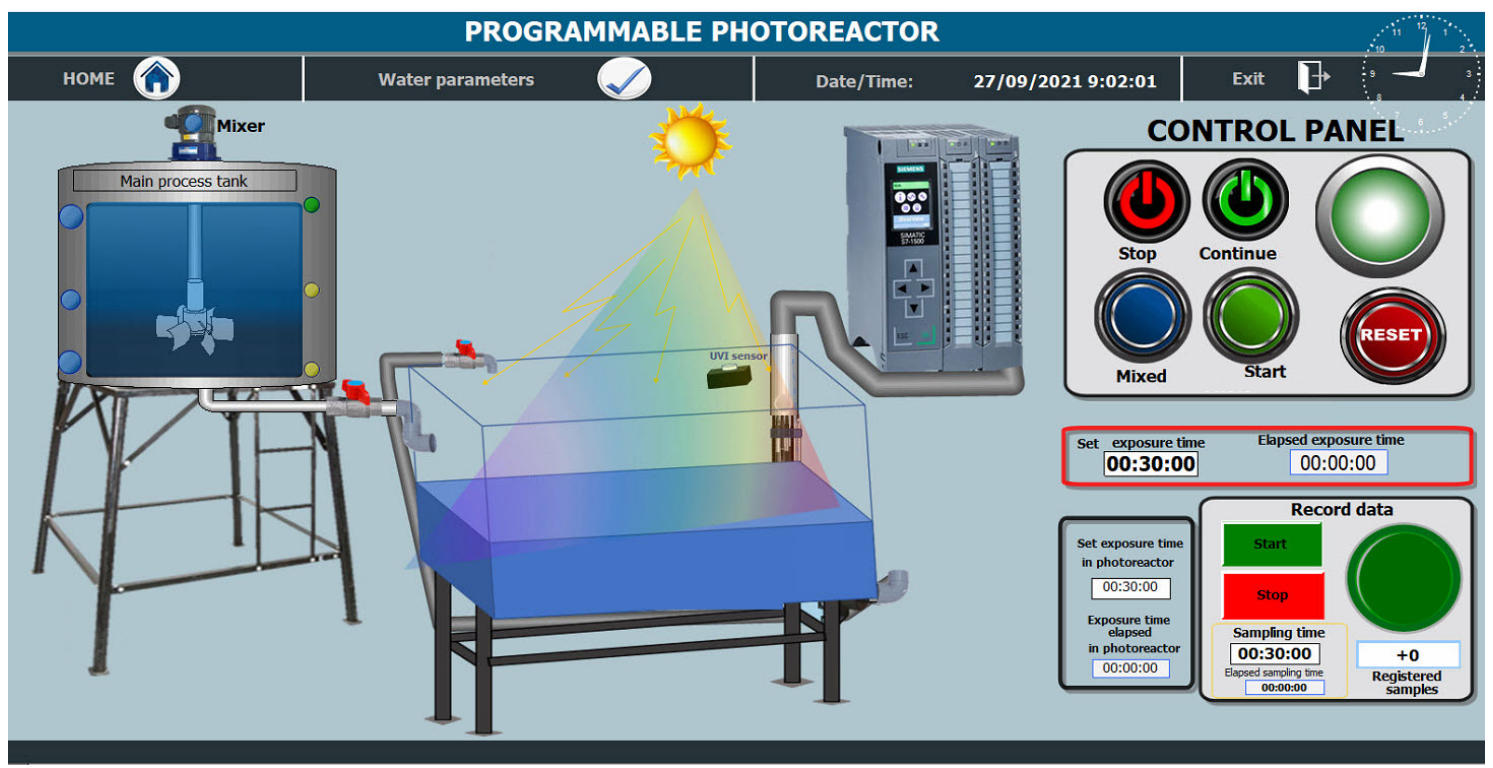

Figure 9. Programmable photoreactor HMI interface

[Matricardi et al., 2018]. Figure 10 shows the result of the characterization of the two mixtures by Raman spectroscopy, presenting the normalized signals with very similar characteristics. The presence of rutile type $\mathrm{TiO}_{2}$ at $444.42 \mathrm{~cm}^{-1}$ and $611.37 \mathrm{~cm}^{-1}$ [Ilie et al., 2017; Tuschel, 2019] is highlighted, both for the mixture of greywater plus $\mathrm{TiO}_{2}$ and for greywater plus $\mathrm{TiO}_{2}$ and gold nanoparticles.

The initial measurements of the different parameters of the units of analysis were made with the following results: $\mathrm{pH}$ 9.80, EC $2800.00 \mathrm{uS} /$ $\mathrm{cm}$, OD $1.30 \mathrm{mg} / \mathrm{L}$ and FCL $3.50 \mathrm{mg} / \mathrm{L}$. These characterizations were similar both for the process composed of greywater $+\mathrm{TiO}_{2}$ (see Table 1), and for the process composed of greywater $+\mathrm{TiO}_{2}$ + gold nanoparticles (see Table 2).

With solar radiation of average UVI of 13.35 , both groups were exposed in the photoreactor, for $30 \mathrm{~min}$ and $60 \mathrm{~min}$, with measurements of the parameters (pH, EC, DO, FCL) every $15 \mathrm{~min}$ automatically from the HMI interface implemented for this purpose, showing differences between the control group and the experimental group.
From Tables 1-2 and Figure 11, the pH of the experimental group exposed to solar UVI radiation for 30 minutes and 60 minutes, shows a decrease in $\mathrm{pH}$ of 0.38 and 0.52 , respectively, which is equivalent to an improvement of the $\mathrm{pH}$ in $5.30 \%$ in 60 minutes. This is due to the degradation of the detergents that are directly related to pH [Gewering et al., 2018; Mohamed et al., 2018].

From Tables 1-2 and Figure 12, the EC of the experimental group exposed to solar UVI radiation for 30 minutes and 60 minutes, presents a decrease in EC of $130.0 \mathrm{uS} / \mathrm{cm}$ and $85.0 \mathrm{uS} / \mathrm{cm}$ respectively, which is equivalent to an $\mathrm{EC}$ improvement of $3.03 \%$ in 60 minutes. EC is related to the amount of salts in water [Çalışkan et al., 2021], which is photodegraded when exposed to solar UVI radiation [Liang et al., 2017].

From Tables 1-2 and Figure 13, the OD of the experimental group exposed to solar UVI radiation for 30 minutes and 60 minutes, presents an increase in OD of $0.25 \mathrm{mg} / \mathrm{L}$ and $0.38 \mathrm{mg} / \mathrm{L}$, respectively, which is equivalent to an improvement in DO of $29.3 \%$ in 60 minutes. This 


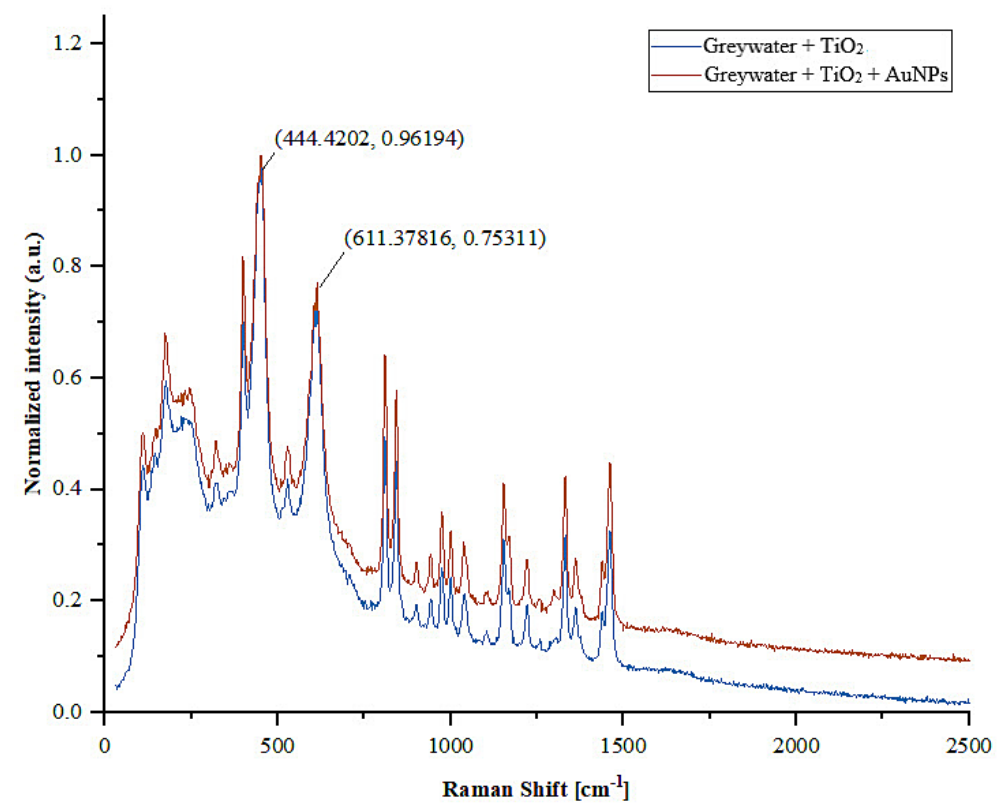

Figure 10. Initial characterization by Raman spectroscopy of greywater mixed with $\mathrm{TiO}_{2}$ and gold nanoparticles

increase in DO occurs due to the continuous recirculation of the water in the photoreactor of Figure 9. The photocatalytic process in the reduction over the $\mathrm{TiO}_{2}$ equivalence band generates oxygen molecules by dissociating from hydrogen [Chen et al., 2020].

From Tables 1-2 and Figure 14, the FCL of the experimental group exposed to solar UVI radiation for 30 minutes and 60 minutes, shows a decrease in FCL of $0.80 \mathrm{mg} / \mathrm{L}$ and $1.25 \mathrm{mg} / \mathrm{L}$, respectively, which is equivalent to an improvement of the FCL in $43.71 \%$ in 60 minutes. This improvement occurs due to the degradation effect of chlorine in the presence of photocatalysts and UV radiation [Cerreta et al., 2019; Q. Sun et al., 2021].

After 60 min of exposure of the greywater to solar radiation with UVI higher than 13, it was re-characterized by Raman spectroscopy. This is show in Figure 15, where the red line indicates a slight attenuation of the physicochemical components of the unit analysis.

Table 1. pH, EC, DO and FCL parameters values of the control group composed of greywater $+\mathrm{TiO}_{2}$, subjected to different periods of exposure in a solar photoreactor

\begin{tabular}{|c|c|c|c|c|c|c|}
\hline Exposure time & $\begin{array}{c}\text { Exhibition time } \\
(\mathrm{min})\end{array}$ & $\mathrm{UVI}$ & $\mathrm{pH}$ & $\begin{array}{c}\mathrm{EC} \\
(\mathrm{uS} / \mathrm{cm})\end{array}$ & $\begin{array}{c}\mathrm{DO} \\
(\mathrm{mg} / \mathrm{L})\end{array}$ & $\begin{array}{c}\mathrm{FCL} \\
(\mathrm{mg} / \mathrm{L})\end{array}$ \\
\hline $11: 30$ & 0 & 13.30 & 9.80 & 2800.00 & 1.30 & 3.50 \\
\hline $11: 45$ & 15 & 13.60 & 8.80 & 2740.00 & 1.71 & 3.20 \\
\hline $12: 00$ & 30 & 13.52 & 8.30 & 2650.00 & 1.60 & 3.00 \\
\hline $12: 15$ & 45 & 13.23 & 8.01 & 2600.70 & 1.57 & 2.77 \\
\hline $12: 30$ & 60 & 13.10 & 7.90 & 2580.00 & 1.54 & 2.55 \\
\hline
\end{tabular}

Table 2. pH, EC, DO and FCL parameters values of the experimental group composed of greywater $+\mathrm{TiO}_{2}+$ gold nanoparticles, subjected to different periods of exposure in a solar photoreactor

\begin{tabular}{|c|c|c|c|c|c|c|}
\hline Exposure time & $\begin{array}{c}\text { Exhibition time } \\
(\mathrm{min})\end{array}$ & $\mathrm{UVI}$ & $\mathrm{pH}$ & $\begin{array}{c}\mathrm{EC} \\
(\mathrm{uS} / \mathrm{cm})\end{array}$ & $\begin{array}{c}\mathrm{DO} \\
(\mathrm{mg} / \mathrm{L})\end{array}$ & $\begin{array}{c}\mathrm{FCL} \\
(\mathrm{mg} / \mathrm{L})\end{array}$ \\
\hline $11: 30$ & 0 & 13.30 & 9.80 & 2800.00 & 1.30 & 3.50 \\
\hline $11: 45$ & 15 & 13.60 & 8.40 & 2600.00 & 1.80 & 3.01 \\
\hline $12: 00$ & 30 & 13.52 & 7.92 & 2520.00 & 1.85 & 2.20 \\
\hline $12: 15$ & 45 & 13.23 & 7.62 & 2510.00 & 1.87 & 2.00 \\
\hline $12: 30$ & 60 & 13.10 & 7.38 & 2495.00 & 1.92 & 1.90 \\
\hline
\end{tabular}




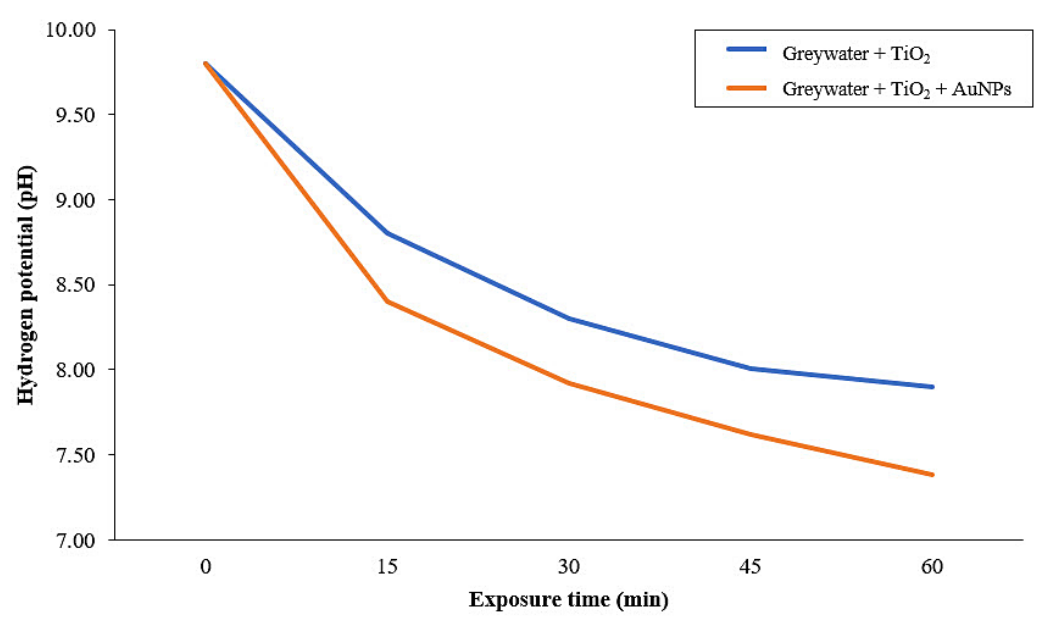

Figure 11. Response of the $\mathrm{pH}$ parameter of greywater mixed with $\mathrm{TiO}_{2}$ and gold nanoparticles exposed to solar UVI radiation for 60 minutes

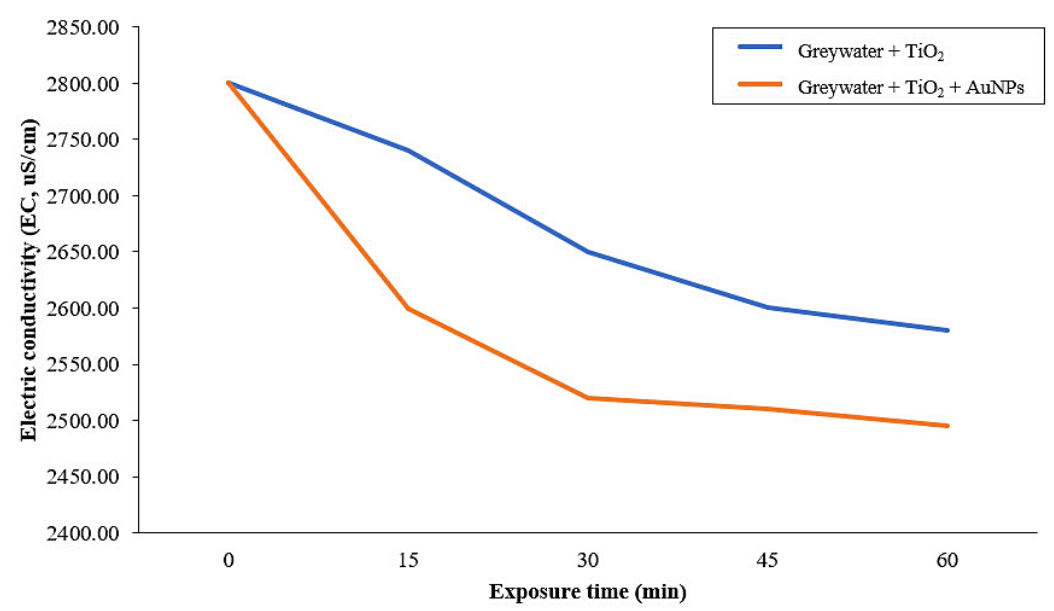

Figure 12. Response of the EC parameter of greywater mixed with $\mathrm{TiO}_{2}$ and gold nanoparticles exposed to solar UVI radiation for 60 minutes

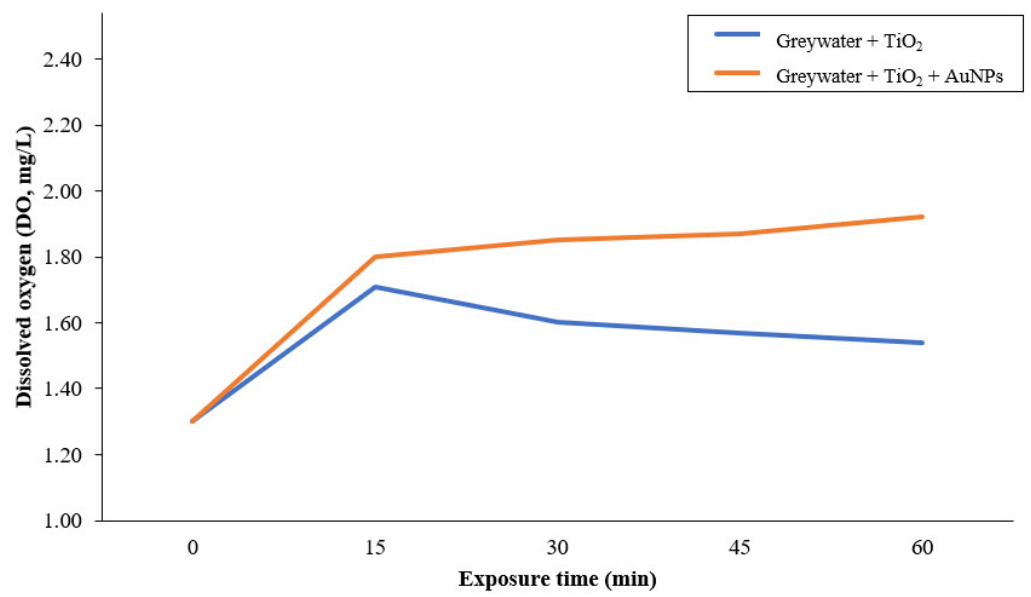

Figure 13. Response of the $\mathrm{DO}$ parameter of greywater mixed with $\mathrm{TiO}_{2}$ and gold nanoparticles exposed to solar UVI radiation for 60 minutes 


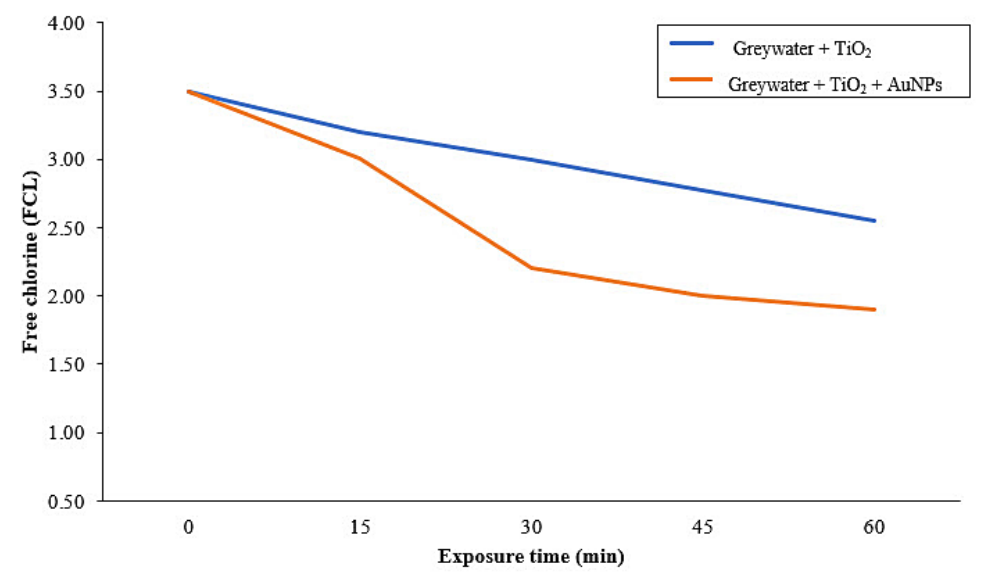

Figure 14. Response of the FCL parameter of greywater mixed with $\mathrm{TiO}_{2}$ and gold nanoparticles exposed to solar UVI radiation for 60 minutes

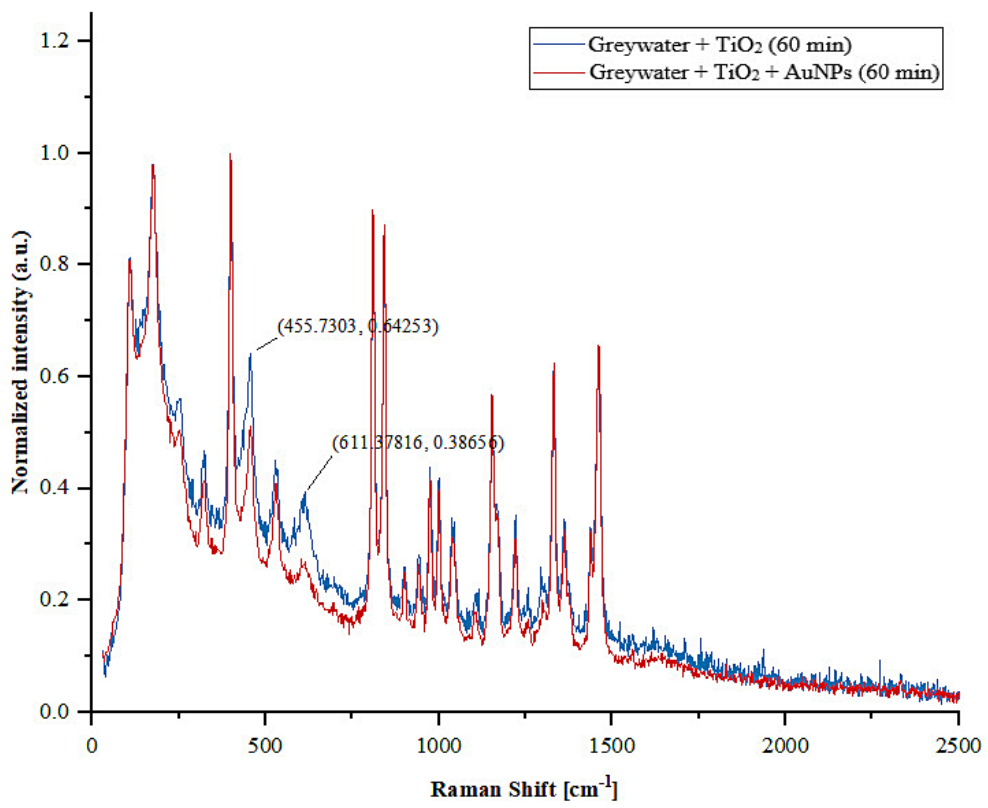

Figure 15. Characterization by Raman spectroscopy of greywater mixed with $\mathrm{TiO}_{2}$ and gold nanoparticles, exposed to solar radiation for $60 \mathrm{~min}$

\section{CONCLUSIONS}

The photocatalytic action of titanium dioxide and gold nanoparticles generated different changes on the physical-chemical parameters of greywater. For an average solar radiation of UVI 13.35 with hourly exposure from 11:30 to 12:30 hours (around solar noon), with the use of the control and experimental groups it was possible to estimate the influence of gold nanoparticles in colloidal state on the photocatalytic action of titanium dioxide for each parameter.

Regarding the $\mathrm{pH}$ in the experimental group, an improvement of $5.30 \%$ was achieved with respect to the control group. The initial $\mathrm{pH}$ decreased from 9.8 to 7.38 in a period of exposure to solar UVI radiation of $60 \mathrm{~min}$. The electrical conductivity (EC) of the experimental group decreased from $2800 \mathrm{uS} / \mathrm{cm}$ to $2400 \mathrm{uS} / \mathrm{cm}$ in the same period of exposure to solar UVI radiation, representing an improvement of $3.03 \%$ with respect to the control group. Dissolved oxygen (DO) presents an improvement of $29.3 \%$ in 60 minutes, increasing in the experimental group from $1.30 \mathrm{mg} / \mathrm{L}$ to $1.92 \mathrm{mg} / \mathrm{L}$, due to the photocatalytic reduction process produced on the $\mathrm{TiO}_{2}$ valence band, generating oxygen molecules by dissociating from hydrogen. The concentration of free chlorine (FCL) in the experimental group improved by $43.71 \%$ with respect to the control group in 
60 minutes; this improvement occurs due to the degradation effect of chlorine in the presence of photocatalysts and UV radiation. These findings were confirmed by Raman spectroscopy applied at the beginning and end of processes in both groups (control and experimental).

Finally, based on the findings for the four parameters in liquid samples belonging to the control group and the experimental group, it was concluded that there is a positive influence of gold nanoparticles on the photocatalytic action of titanium dioxide in the physical-chemical parameters of greywater, which contributes to the improvement of water quality.

\section{Acknowledgements}

This work was possible owing to funding from the Universidad Nacional de Huancavelica-Peru through the Economic Support Fund for Research Professors (FAEDI). Likewise, the "Facultad de Ingeniería Electrónica - Sistemas" is thanked for the help with the necessary equipment for the implementation of the photoreactor.

\section{REFERENCES}

1. Abdel-Maksoud, Y.K., Imam, E., \& Ramadan, A.R. (2018). $\mathrm{TiO}_{2}$ water-bell photoreactor for wastewater treatment. Solar Energy, 170, 323-335.

2. Almomani, F., Bhosale, R., Kumar, A., \& Khraisheh, M. (2018). Potential use of solar photocatalytic oxidation in removing emerging pharmaceuticals from wastewater: A pilot plant study. Solar Energy. https://doi.org/10.1016/J.SOLENER.2018.07.041

3. Amendola, V., \& Meneghetti, M. (2009). Size evaluation of gold nanoparticles by UV- vis spectroscopy. The Journal of Physical Chemistry C, 113(11), 4277-4285.

4. AVANTES. (2019). Raman Spectroscopy Applications. https://avantesusa.com/ raman-spectroscopy-applications/

5. BOPLA. (2019). Grado de protección IP 68. https:// www.bopla.de/es/datos-tecnicos/informacionestecnicas/grados-de-proteccion/ip-68.html

6. Boyd, C.E. (2020). Water quality. U. Auburn (Ed.); 3.a edition. Springer. https://doi. org/10.1007/978-3-030-23335-8

7. Çalışkan, Y., Öztürk, H., Bektaş, N., \& Yatmaz, H. C. (2021). UVA enhanced electrocoagulation comparing $\mathrm{Al}$ and $\mathrm{Fe}$ electrodes for reclamation of greywater. Separation Science and Technology, 56(9), 1622-1632.
8. Carbajal-Morán, H., Zárate Quiñones, R.H., \& Márquez Camarena, J.F. (2021). Gray Water Recovery System Model by Solar Photocatalysis with $\mathrm{TiO} 2$ Nanoparticles for Crop Irrigation. Journal of Ecological Engineering, 22(4), 78-87. https://doi. org/10.12911/22998993/134034

9. Cerreta, G., Roccamante, M.A., Oller, I., Malato, S., \& Rizzo, L. (2019). Contaminants of emerging concern removal from real wastewater by UV/ free chlorine process: A comparison with solar/free chlorine and $\mathrm{UV} / \mathrm{H} 2 \mathrm{O} 2$ at pilot scale. Chemosphere, 236, 124354.

10. Chen, X., Yao, J., Xia, B., Gan, J., Gao, N., \& Zhang, Z. (2020). Influence of $\mathrm{pH}$ and DO on the ofloxacin degradation in water by UVA-LED/TiO2 nanotube arrays photocatalytic fuel cell: mechanism, ROSs contribution and power generation. Journal of hazardous materials, 383, 121220.

11. Das, R.S., \& Agrawal, Y.K. (2011). Raman spectroscopy: Recent advancements, techniques and applications. Vibrational Spectroscopy, 57(2), 163-176. https://doi.org/https://doi.org/10.1016/j. vibspec.2011.08.003

12. de Oliveira Schwaickhardt, R., Machado, Ê.L., \& Lutterbeck, C.A. (2017). Combined use of VUV and UVC photoreactors for the treatment of hospital laundry wastewaters: Reduction of load parameters, detoxification and life cycle assessment of different configurations. Science of the Total Environment, 590, 233-241.

13. ElectroPeak. (2016). Interfacing UVM30A UV Sensor Module with Arduino - Electropeak. https:// electropeak.com/learn/interfacing-uvm30a-uvlight-sensor-module-with-arduino/

14. EMRC. (2011). Reuse of Greywater in Western Australia. Discussion Paper Australia.

15. Gewering, T., Januliene, D., Ries, A.B., \& Moeller, A. (2018). Know your detergents: A case study on detergent background in negative stain electron microscopy. Journal of Structural Biology, 203(3), 242-246.

16. Hou, J.G., Yang, J.L., Luo, Y., Aizpurua, J., Liao, Y., Zhang, L., Chen, L.G., Zhang, C., \& Jiang, S. (2013). Chemical mapping of a single molecule by plasmon-enhanced Raman scattering. Nature, 498(7452), 82-86. https://doi.org/10.1038/ nature 12151

17. Ilie, A. G., Scarisoareanu, M., Morjan, I., Dutu, E., Badiceanu, M., \& Mihailescu, I. (2017). Principal component analysis of Raman spectra for $\mathrm{TiO} 2$ nanoparticle characterization. Applied Surface Science, 417, 93-103. https://doi.org/https://doi. org/10.1016/j.apsusc.2017.01.193

18. Liang, Y., Zhu, H., Bañuelos, G., Yan, B., Shutes, B., Cheng, X., \& Chen, X. (2017). Removal of nutrients in saline wastewater using constructed wetlands: 
Plant species, influent loads and salinity levels as influencing factors. Chemosphere, 187, 52-61.

19. Lin, L., Wang, H., Jiang, W., Mkaouar, A.R., \& Xu, P. (2017). Comparison study on photocatalytic oxidation of pharmaceuticals by $\mathrm{TiO} 2-\mathrm{Fe}$ and $\mathrm{TiO} 2-\mathrm{re}-$ duced graphene oxide nanocomposites immobilized on optical fibers. Journal of hazardous materials, 333, 162-168.

20. Mansfeldova, V., Zlamalova, M., Tarabkova, H., Janda, P., Vorokhta, M., Piliai, L., \& Kavan, L. (2021). Work Function of $\mathrm{TiO}_{2}$ (Anatase, Rutile, and Brookite) Single Crystals: Effects of the Environment. The Journal of Physical Chemistry C, 125(3), 1902-1912.

21. Matallana-Surget, S., \& Wattiez, R. (2013). Impact of solar radiation on gene expression in bacteria. Proteomes, 1(2), 70-86.

22. Matricardi, C., Hanske, C., Garcia-Pomar, J.L., Langer, J., Mihi, A., \& Liz-Marzan, L.M. (2018). Gold nanoparticle plasmonic superlattices as surface-enhanced Raman spectroscopy substrates. ACS nano, 12(8), 8531-8539.

23. Mohamed, R.M., Al-Gheethi, A.A., Noramira, J., Chan, C.M., Hashim, M.K.A., \& Sabariah, M. (2018). Effect of detergents from laundry greywater on soil properties: a preliminary study. Applied water science, 8(1), 1-7.

24. Plantard, G., Dezani, C., Ribeiro, E., Reoyo-Prats, B., \& Goetz, V. (2021). Modelling heterogeneous photocatalytic oxidation using suspended $\mathrm{TiO}_{2}$ in a photoreactor working in continuous mode: Application to dynamic irradiation conditions simulating typical days in July and February. Canadian Journal of Chemical Engineering, 99(1), 142-152. https:// doi.org/10.1002/cjce. 23870

25. Raman, C.V, \& Krishnan, K.S. (1928). A New Type of Secondary Radiation. Nature, 121(3048), 501-502. https://doi.org/10.1038/121501c0

26. REMOND. (2019). Water quality analysis. https:// remond.en.alibaba.com/es_ES/?spm=a2700. icbuShop.88.7.20674367QPvkOI

27. Rueda-Marquez, J.J., Levchuk, I., Ibañez, P.F., \& Sillanpää, M. (2020). A critical review on application of photocatalysis for toxicity reduction of real wastewaters. Journal of Cleaner Production, 258, 120694.

28. Sun, J., Gong, L., Wang, W., Gong, Z., Wang, D., \& Fan, M. (2020). Surface-enhanced Raman spectroscopy for on-site analysis: A review of recent developments. Luminescence, 35(6), 808-820.

29. Sun, Q., Wu, S., Yin, R., Bai, X., Bhunia, A.K., Liu, C., Zheng, Y., Wang, F., \& Blatchley III, E.R. (2021). Effects of fulvic acid size on microcystinLR photodegradation and detoxification in the chlorine/UV process. Water Research, 193, 116893.

30. Tuschel, D. (2019). Raman spectroscopy and polymorphism. Spectroscopy, 34(3), 10-21.

31. Yamamoto, A.L.C., Corrêa, M.P., \& Ccoyllo, O.R. S. (2018). Validation and analysis of UV radiation time series collected in different peruvian sites.

32. Zhang, Q., Lu, X., Tang, P., Zhang, D., Tian, J., \& Zhong, L. (2016). Gold nanoparticle (AuNP)based surface-enhanced Raman scattering (SERS) probe of leukemic lymphocytes. Plasmonics, 11(5), 1361-1368. 